\title{
Consumers Knowledge regarding Pesticides on Apples and Effective Washing to remove the Pesticides.
}

\author{
Arvinder Brar ${ }^{1}$, Bobby Sidhu ${ }^{2}$ \\ ${ }^{1}$ Lead Author, B. Tech. Student, School of Health Sciences, British Columbia Institute of \\ Technology, Burnaby, BC
}

\section{Abstract}

Objectives: With the increased health awareness, there is a growing demand of fresh produce in food. Not only is there a possibility of the fresh produce to be contaminated with harmful microorganisms, but also chemicals such as pesticides that have harmful adverse effects. The effective method of washing the fruit can reduce the level of pesticide residue to a significant amount. The objective of the study is to determine if the general public is aware of washing the produce properly and if knowledge, age, gender, education or concerns have any association with the effectiveness of washing.

Methods: The study was done using a survey that was designed using Google Forms. An online survey which was self-administered was sent out using snowball sampling. The survey was publicized through both email and social media Facebook. The survey had 19 questions in total 11 of which were general and 8 were knowledge based. The results were analysed by Chi-square test using NCSS Software Package.

Results: It was found that there is a statistically significant association between knowledge level and effective method of washing the apples with a $\mathrm{p}$-value of 0.00082 . This means $\mathrm{H}_{0}$ is rejected; hence it means there is an associative between knowledge level and effectively washing the apples. No other demographic factors (age, gender, education, concerns, or having children) were found to be associated with the method of washing the produce effectively.

Conclusion: It was found through the study that the people who were aware and had good knowledge about the presence of chemicals (pesticides) on apples would wash their fruit (apples) effectively enough that will reduce the pesticide residue on fruits more than people who aren't aware of the pesticides on fruits. Other factors such as age, gender, preference for the type of food were not found to have any association with washing of the fruit effectively or higher level of knowledge.

Keywords: apples, washing, pesticides, knowledge 


\section{Introduction}

The demand for foods free of harmful chemicals is high because of the emergence of new chronic diseases that may be linked to certain chemicals. There are many challenges to ensuring foods are free of harmful chemicals especially when they are grown and shipped across continents. Many consumables are found to contain various types of chemicals such as pesticides, insecticides, fungicides, heavy metals, antibiotics, dioxins, etc. The pesticides are a necessary and important part of the agricultural practices that take place world across. But at the same time there are numerous ill effects associated with the use of pesticides which range from short-term acute toxic effects to long-term chronic toxic effects. To control the use of pesticides and their adverse consequences, there are various federal and provincial acts that ensure the application of pesticides within the safe limits. Despite all these precautionary provisions, a large number of chemicals still end up on our foods, especially fresh fruits and vegetables. It is assumed that simple home processing of the produce in some way like washing, rubbing, peeling, soaking, etc. reduces the pesticide residue on it. Research shows that the various methods of washing reduce the pesticide residue on produce to different extent.

\section{Literature Review}

Pesticides are the chemicals that are used to protect crops from various diseases and external agents such as weeds, herbs, insects or pests. Pesticides are a broad range of chemicals that include insecticide, fungicide, bactericide, herbicide, rodenticide, miticide, algicide, avicide, nematicide, molluscicide and piscicide (Ministry of Agriculture and Lands, 2009) Pesticides are essential in protecting food crops all over the world. Such chemicals enable growers to produce mass quantities of foods for large populations at reasonably low costs. The use of pesticides have advantages to agriculture practice such as "controlling agricultural pests (including diseases and weeds) and vectors of plant disease, controlling human and livestock disease vectors and nuisance organisms and preventing or controlling organisms that harm other human activities and structures"'(Cooper and Dobson, 2007). In addition to above mentioned primary benefits, there are some secondary benefits too, such as food safety, food security, national agricultural economy and assured safe and diverse food supply. Some of the primary and secondary benefits are summarized in Figure1 which shows that there are inevitable secondary benefits to the farming community in addition to national and global benefits. After the produce or crops are harvested, packaged and transported, pesticide residues remain on the agricultural commodities and contribute to the total dietary intake. All these residual pesticides end up in the produce and need to be removed by effective washing methods. 


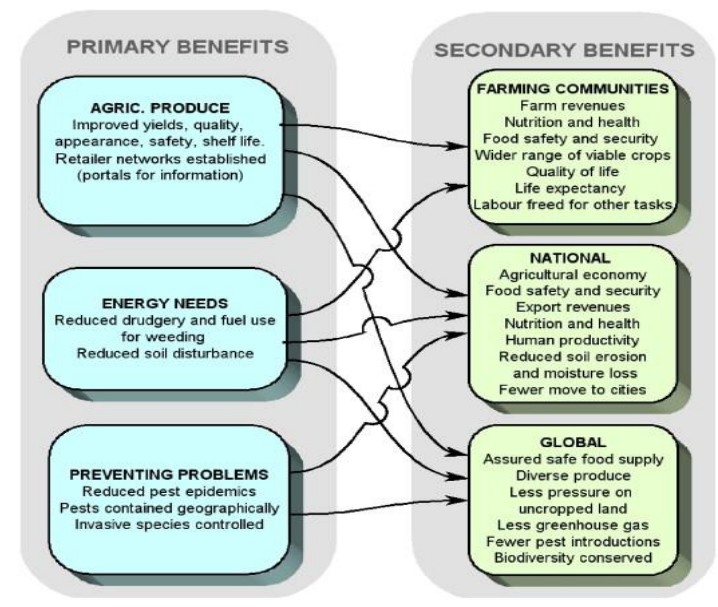

Figure 1: Benefits of using Pesticides: Primary and Secondary (Cooper and Dobson, 2007)

\section{Public Health Concerns}

The pesticide residue found on food pose various concerns for the general population due to the harmful effects and risks generally associated with them. A number of studies have found certain pesticides associated with carcinogenicity, immunetoxicity, neurotoxicity, behavioral impairment, reproductive dysfunction, endocrine disruption, developmental disabilities, skin conditions and respiratory diseases (Kong, 2012). Recently, the pesticides have been associated with depression symptoms as well. (Bienkowski, 2014).

Scientists now recognize that children are more vulnerable as compared to adults to environmental contaminants such as xenobiotics (foreign chemicals in the body) that include pesticides and heavy metals. Children are found to be more vulnerable as they may have greater risk of exposure due to their physiology. (Weir, 2002) The exposure of many common pesticides may impact central nervous system in children since the brain is not fully developed (Lozowicka, 2014) and have a permeable blood brain barrier (Arya, 2005). They take in more air, food and water per body weight than adults and hence greater amount of substances like pesticides with that. Also, the detoxifying mechanism is not fully developed in children rendering them incapable to get rid of toxic effects (Lozowicka, 2014). Hence, there is a need that restrictions be placed on the use of nonessential chemical pesticides and to reduce the intake/exposure of chemicals through potential pathways.

Although pesticide levels on foods do not exceed the limits prescribed most of the time; scientists and environmentalists believe that miniscule amounts of pesticide consumed repeatedly may still pose health risks. Not many studies or tests have been conducted to examine how low levels of different chemicals interact with each other when consumed by humans (Perkel, 2006). Also, a number of new pesticides that are used now a days are relatively safe but some pesticide accumulate in the environment over time e.g. myclobutanil. Fruit and vegetables have been found to contain pesticide residue and traces of heavy metals. Also, certain chemicals banned in other countries are still in use in Canada; one such example is Atrazine which is used on corn. (Luymes, 2007)

All these health concerns discussed above emphasize the fact that harmful chemical such as various pesticides can affect health adversely over short or long term. The outcome of these affects could not be visible for many years or generations to come, unlike many bacterial infections which have short term affects and person can develop immunity to those. The health 
effects of pesticides are difficult to measure and track over time. The risk can be minimized to some extent by effectively washing the produce to remove these 'xenobiotics' to some extent.

\section{Applicable Legislations}

The presence of pesticides on food is a major concern. Hence controlling pesticide levels in foods is really important for public health. Governments and regulators have set limits for use of pesticides on the food crops. In Canada, Health Canada evaluates the acute and chronic effects of pesticides and set limits on types and quantities of pesticides that can be used for different crops. The maximum amount of residue expected is legally established as maximum residue limit (MRLs). (Health Canada, 2012)

The use of pesticides is regulated and enforced in Canada by Canadian Food Inspection Agency. The Canadian Food Inspection agency and various other bodies of the government regulate the pesticide use in Canada (Canadian Food Inspection Agency). The legislations that apply to pesticide use are: Pests Control Products Act and Regulations, Integrated Pest Management Act and Regulation, Hazardous Products Act, Food and Drug Act and Regulations and Food Safety Act. (Ministry of Agriculture and Lands, 2009). The Food and Drugs Act is the one that ensures that the pesticide residue on all types of foods is within the Maximum Residue limit (MRL) and only such foods that meet the criteria are allowed to be sold in Canada (section 4 (2)). The Food and Drug Regulations says that for the chemical for which no MRL is specified in the act it should not exceed 0.1 parts per million concentration on food (Division 15 section 1(a)). The Pest Control Products Act is one of the important acts with respect to pest control chemicals. This act regulates all the products of pest control by registration of the pest control products and specifying the maximum residue limits. This act is also responsible for enforcement of MRLs. Its purpose is to ensure the protection of human health and the environment. The Pest Control Products Regulations is responsible for pesticide registration by evaluation of the maximum residue limits for different new pesticides and regulate the labelling, etc. In BC, Integrated Pest Management Act and Regulation regulates the sale of pesticide and use/application of pesticides and issue licenses and permits for the sale and use.

In addition, BC Ministry of Agriculture updates all the information of new registrations on a document called Pesticide Registration. This document contains a list of all the pesticides that have been approved to date that can be used on any type of produce or crop (BC Ministry of Agriculture)

All the above regulations are mandated in Canada for the pesticide use in any form. Although there are a number of such regulations in place, but it has been found repeatedly that the agricultural crops exceed safe limits. It might not be only due to overuse but also due to wind drift, soil erosion, agricultural runoffs, heavy rains or due excessive level of pesticides in the soil due to previous uses. Therefore, the effective washing becomes important at the 
consumers' end to reduce the levels prior to consumption.

\section{Why Apples?}

A study done by the US based environmental group found pesticides levels detected on apples to be the highest as compared to other foods (Looney, 2013). Also, US Department of Agriculture's Pesticide Data Program (PDP) tests the food commodities for pesticide levels and 2010 Annual Summary confirmed that apples in US are found to have large number of pesticides on them. The tests found that 47 different pesticide residues were found on apples (Pesticide Action Network North America). This is probably because apple crops are affected adversely by many diseases. Such diseases include common fungal and bacterial infections like apple scab, powdery mildew, blight, apple rust, bitter rot and sooty blotch (Ritchie, et.al. 2012). Apple maggots and codling moth are the two common pest infestations for apple crops (Ritchie, et.al. 2012). In BC apple orchards, common diseases and pests found are codling moth, apple clearwing moth, aphids, scab, brown rot, blight, powdery mildew, etc. (Pesticide Registration, 2014). One of the newer problems that have been identified by CFIA is apple maggots (Rhagoletis pomonella). It was first detected in BC in 2006 and since then it has spread in many areas of fruit production in BC such as the Okanagan, Similkameen and Creston valleys. To contain the disease in the area and prevent it from spreading further, CFIA recommends the use of controlled products like insecticides and pesticides to protect apple crops in those areas (BC Ministry of Agriculture, 2013). The pesticides use to control this novel disease yet add to the overall concentration of pesticides that ends up in our produce and in our diet in turn.

Altacor, Success, Nova, Flint, Delegate, Luna Privelege, Allegro and Rimon are few of the registered pesticides that are used by apple growers in BC Interior. Out of the many chemicals used, the two commonly used pesticides in BC are Altacor (active chemical agent chlorantraniliprole) and Nova (active chemical agent myclobutanil). Altacor is an insecticide and Nova is a fungicide. These two chemicals are used close to harvest period and are used to combat more than one disease. In addition to pre-harvest application of pesticides, there are some pesticides that are applied post harvest too. (BC Ministry of Agriculture). Out of the various pesticides found on apples in US, diphenyamine and thiabendazole (Pesticide Action Network North America, What's on my food?) top the chart as they were found in more than 80\% samples (USDA, p 24, 73, 2010). Both of the above mentioned pesticides are relatively new as they were approved after 2010 to be used for apple fruit (BC Ministry of Education). Since these chemicals are fairly new for the researchers, not too many studies are done about acute and chronic effects of these chemicals on human health.

Myclobutanil has relatively low acute toxicity but chronic toxicity tests have proven developmental and reproductive toxicity (Kegley et al, 2014). The fewer chemical studies done on these newer chemicals give a perception of being less hazardous (Pesticide Action Network North America, Limitation of the ecotoxicity data). The USDA also confirms the above fact but 
in addition suspects it to be harmone disruptor. On the other hand, the pesticide of study Chlorantraniliprole is not found to have any significant health concerns by USDA, whereas PANNA identifies it as a potential ground water contaminant. No data is available to decide about developmental or reproductive toxicity and hormone/endocrine disruption (Kegley et al, 2014). US EPA claims that the exposure to Chlorantraniliprole through food and water is within the established limits and there is no acute or chronic toxicity risk (USEPA, 2008). It is concluded here that since these two chemicals do not have a lot of research data available and/ or availability of acute toxicity data does not imply that these chemicals cannot harm the health adversely in the long term.

\section{Previous Research}

As discussed above, it is appropriate to conclude that the chemicals that are used to improve harvest and combat diseases have adverse health effects, and the produce as is available in stores has pesticide residue on it which is consumed by the general public. To get rid of pesticides some sort of treatment needs to be done such as washing, scrubbing, using commercial products/ solvents to remove contaminants. A number of studies done previously show that washing the apples actually reduces some amount of pesticides but not the entire residue (Kong et al., 2012, Dorothea et al.,2008 and Walter et al., 2000 ). Depending on the type of chemistry of the molecule, various pesticides will have different solubility in water.
In a study done in China in 2012, pesticide residue of chlorpyrifos, $\mathrm{B}$ cypermethrin, tebuconazide, acetamprid and carbendazim were studied. The percentage removed after each of the following steps were calculated to determine the effectiveness of home processing of apples which involved: unwashed - unpeeled, peeling, coring and juicing, and washed unpeeled, peeling, coring and juicing. After the washing step the mean losses in pesticide residue were in range of 7\%-48 \% in those that had the recommended doses applied to the fruit. The differences in the obtained results were attributed to the water solubility of pesticide. However, the amount removed after washing of a pesticide is not correlated with its water solubility but it was concluded that the concentration of above five pesticides reduced significantly after washing and other steps of processing. (Kong et al., 2012)

In another study specifically done on Captan in Quebec Canada similar results were found. In this study, 212 samples of apples from commercial orchards were collected and analysed for chemical agent in no post harvest treatment, rinsed and rinsedpeeled apples. A 50\% reduction in pesticide residue was found in apples rinsed in deionized water and rubbed with hands as compared to apples with no post treatment. Whereas apples that were rinsed and peeled resulted in nearly complete removal of Captan (up to 98\%) (Dorothea et al., 2008) Yet another study done to establish the effect of rinsing on produce gave interesting results. 14 different fruits and vegetables were used to get 258 samples which were studied for 12 different 
pesticides. Most of the pesticides supported the hypothesis that the pesticide residues decrease upon rinsing the produce under tap water. Conversely, there were three pesticides: chlorpyrifos, bifenthrin and vinclozolin that showed no significant reduction upon rinsing under tap water. It was concluded through this study that water solubility is not the factor responsible to remove pesticides from food crops and also, much shorter time of rinsing i.e. 30 seconds could remove most of the pesticides. (Walter et al., 2000)

The studies provide a solid ground to assume that the entire pesticide residue is not removed after washing or rinsing. But there is definitely reduction in pesticide residue after simple rinsing. Contrary to what one can assume, water solubility is not the only factor involved.

In one study, it was found that washing apples under tap water for 15 seconds and wiping with towel significantly reduced the pesticide residue concentration. In contrary, simply washing apples with tap water and then letting them dry over counter didn't reduce pesticide concentration significantly. (Ramusssen, et al. 2003)

Researchers have made attempts from examine the effect of various other techniques of washing such as using produce brushes and other produce cleaner (solution). The following study tested the effectiveness of using various techniques in washing, namely: "produce brush, produce cleaner, produce cleaner with paper towel wipe, and water wash and paper towel wipe." (Michaels, et al. 2003) Apples were also tested in waxed and unwaxed states. Out of the various household cleaning methods, the method of washing and drying with paper towel was found to be more effective than produce cleaners, produce brushes and rinse followed by air drying. It was also found that any methods "involving wiping with paper towels increased effectiveness over similar controls with double wash and paper towel drying." Interestingly, the use of brushes should be discouraged as it was found that although the chemical contaminants were reduced but brushes were contaminated with the microorganisms. (Michaels, et al. 2003) Figure 2 summarizes the results.

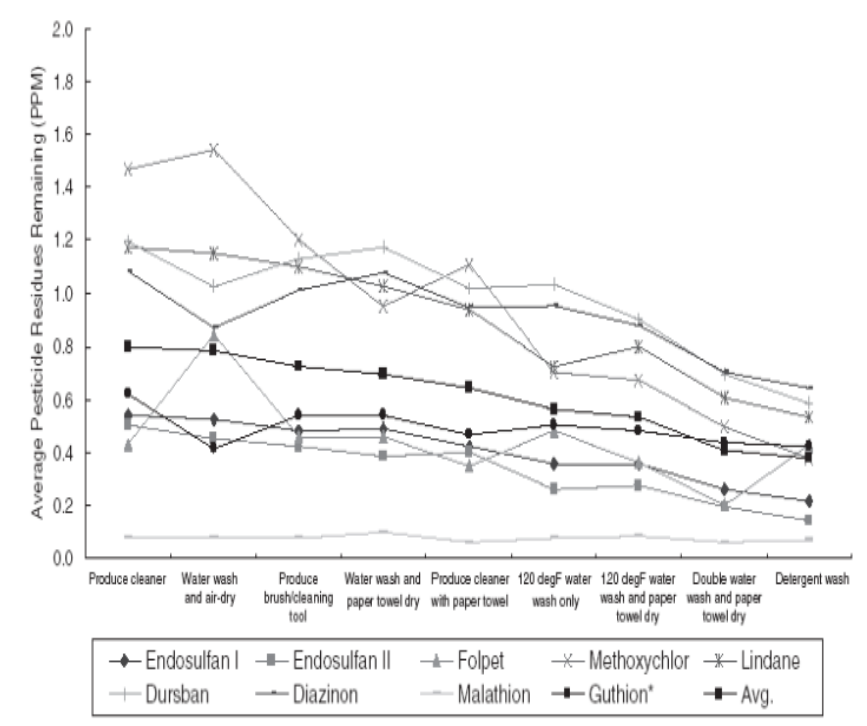

Figure 2: Efficiency of produce cleaning methods based on use of apples contaminated with pesticide (p.p.m. of pesticide on waxed and unwaxed apples) (Michaels, 2003)

\section{Purpose of the study}

With the increased health awareness, there has been increased consumption of fresh produce. The pesticide residue levels have always been health concern and hence it is extremely important to be diligent to effectively wash the produce to get rid of pesticides. The foremost need recognized by author was to analyze if the public is aware 
of the pesticides on apples and effectiveness of washing those to get rid of pesticides.

Hence, the purpose of the study is to determine the proportion of population that effectively washes the produce and association between various parameters such as age, gender, knowledge and concern.

\section{Research Question}

To determine if there is any association between effective washing of the apples that would result in the reduction of pesticide residue on apples and age, gender, concerns, education and knowledge level about chemicals on apples.

\section{Materials and Methods}

In the research study, the survey was conducted to gather the information regarding the perception and knowledge of the general public about the effects of pesticides and its association to the styles of washing. A survey is "a method of gathering information from a sample of individuals [where] this 'sample' is usually just a fraction of population being studied." The main intent of the information gathered that way is not to test the individual or describe the individual in any way rather it is to collect the overall profile of the population. (Scheuren, 2004)

The survey was designed to be a sample survey in which "data [is] collected for only a fraction (typically a very small fraction) of units of the population". (Statistics Canada, 2010) Overall, the survey design consisted of some general questions that helped to analyze the behaviour and yet other questions tested the knowledge. The survey called "Survey on Awareness of Chemicals on Apples and Effective Ways of
Washing" was completed by the participants of the study, and no questions or aspects of the survey were changed during the data collection period.

The method that was utilized for this research project was a survey that was a self-administered questionnaire in a computerized format. The questionnaire survey is the one which consists of "a group or sequence of questions designed to obtain information on a subject from a respondent". (Statistics Canada, 2010) The questionnaire was created using a tool by Google called Google Forms. The questionnaire contained 19 questions. Out of those, eleven of which were general questions regarding the background information and behaviour and eight were knowledge based questions. The questions were developed in such a way that survey respondents can understand the questions and provide the correct answers easily that is suitable for subsequent processing and analysis of the data

The questionnaire was distributed through email and through Facebook. The link to the survey was sent to the contacts through email along with the consent form with all the details. Similarly, an internet link to the online survey was posted on Facebook along with the shorter Consent Letter. This was done to attract potential respondents to complete the survey. Data was collected from 60 respondents. Google form where survey was collected was linked to a spreadsheet in Google Sheets. The raw data was then analysed using Excel and NCSS Software Package. 


\section{Results}

\section{Descriptive Statistics}

The type of data that was collected in the study was nominal data. Both dichotomous and multichotomous data was collected. Once all the data was collected using survey, percentages and means were calculated for the descriptive data analysis. Since, measures of central tendency and spread didn't produce any significant information, therefore were not used.

From the descriptive data from 73 respondents, it was found that $56 \%$ were females and $44 \%$ were males. Out of all the respondents $30 \%$ have children. It was also interesting to note that majority $(51 \%)$ of the respondents doesn't have any specific preferences for organic or conventional apples, rather they would consume both. In terms of washing the apples effectively, 56\% respondents always washed their apples before consuming whereas $14 \%$ would either never wash or rarely wash their apples. Moreover, $49 \%$ of the respondents would only wash or rinse their apples with tap water which is a lesser effective way as opposed to washing and then wiping/drying the apples with a paper towel.

Also, from the descriptive statistical results it was found that the majority of the people got a knowledge score of 5 and second to that were the numbers of people scoring 6 and 7 .

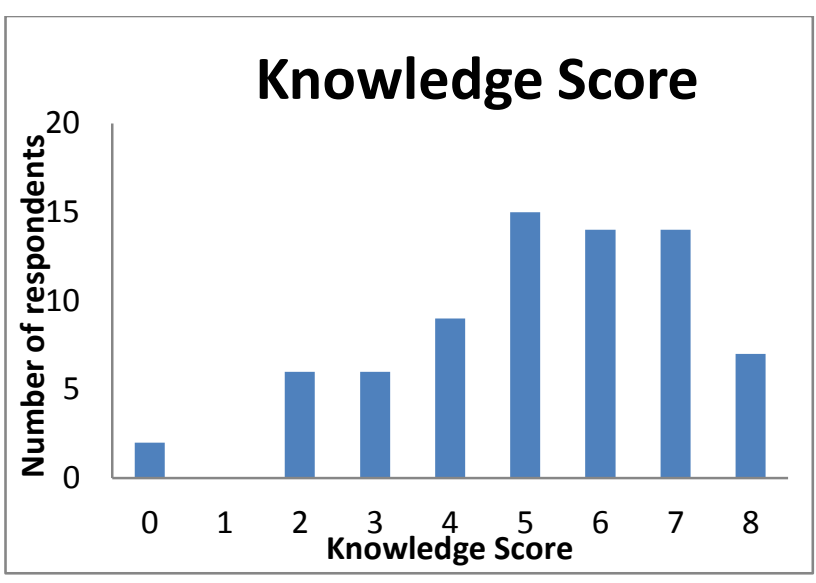

Figure 3 graph of number of respondents vs. the knowledge score achieved.

\section{Inferential Statistics}

The Chi square tests were done to determine if there is association between the various parameters. Several tests were run to find if there is any association between effectively washing the apples and their knowledge, age, gender, education, type of fruit purchased and concern. Several other tests were run to find out if the association between particular knowledge question and effectiveness of washing the apples. Score of the knowledge questions was added and people who scored 7 or above were considered knowledgeable.

\section{Statistical Data and Interpretation}

For the purpose of the study, Statistical package NCSS was used to analyse the results using Chi-Square tests. It was found from the results of the Chi square tests that there is as association between the knowledge level of chemicals on apples and effective washing of the fruit. The $p$-value of the test was found to be 0.00082 using the Pearson's Chi-square test. 


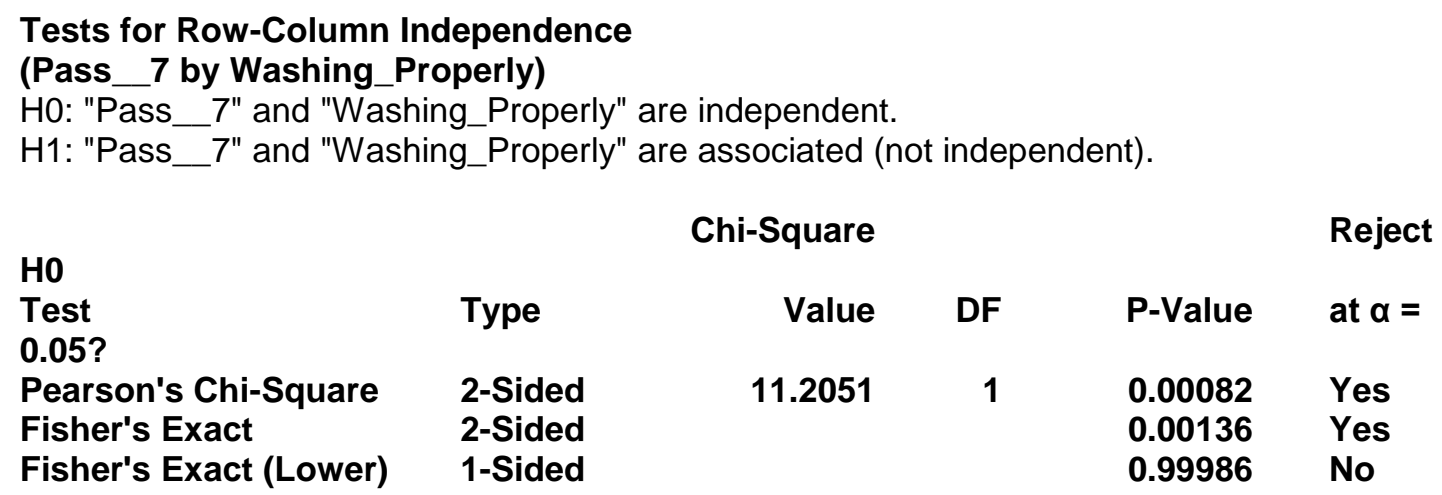

Chi-Square

Reject

Value DF P-Value at $\alpha=$

11.2051

1

$\mathbf{0 . 0 0 0 8 2}$ Yes

$\mathbf{0 . 0 0 1 3 6}$ Yes

0.99986 No

Since the p-value is less than 0.5 , therefore $\mathrm{H}_{0}$ was rejected. It was concluded that there is an association between the knowledge score and washing apples properly.

All the other parameters or demographics were found to have no association with effective washing or knowledge level of the respondents.

Alpha Error: In the study it was unlikely to have alpha error. The alpha error occurs when the null hypothesis is incorrectly rejected; rather the null hypothesis is in fact true. The alpha error is minimized by lowering the acceptable alpha from 0.05 to 0.01 . Actually, the p-value for association of knowledge level and effective washing was 0.00082 which is significantly lower than 0.01 . Therefore, it is unlikely to have an alpha error, which means we have correctly rejected the null hypothesis.

Beta Error: In this study there was a possibility of beta error for the tests. Beta error occurs when the study fails to reject the null hypothesis and the association likely exists. To gain more certainty and to reduce beta error, the sample size should be increased.

\section{Discussion}

The statistically significant association between the knowledge score and effectiveness of washing the fruit indicates that the respondents who were well aware of the chemicals on fruits (apples) were more diligent to take actions i.e. washing the fruit effectively to minimize the intake of chemicals in their diet. Also, statistics from the study show that majority of respondents (49\%) were washing the fruit with water only and didn't use paper towel to dry the fruit which is not sufficient to remove pesticides with maximum effectiveness as per literature. (Michaels, etal. 2013). In addition, 58\% washed their fruit for less than 10 seconds and only $21 \%$ washed their fruit for more than 10 seconds, although $79 \%$ of the respondents have shown some concern of harmful chemicals or microbes on the fruit. This suggests that people are, in general, concerned but there is a knowledge gap as to what could be done to resolve the concern such as washing the fruit under tap water for at least 10 seconds and then drying the fruit with a paper towel as the appropriate way(Michaels, etal. 2013).

The other factors such as age, having a child or not, gender, educational level were 
not found to be associated with effective washing of the fruit. This is contrary to another research survey focusing on consumer handling of fresh fruits and vegetables where "the results from the study suggested that women, lower-income households, people 65 years and older, and non-college graduates practice safer food handling methods than men, higher-income households, people younger than 65 years, and college or postcollege graduates". (LiCohen and Bruhn, 2002). The nonconformance with the literature could be addressed by increasing the sample size and randomness of the study to get respondents from various categories to analyze. On the contrary, the results were close when it came to percentage of respondents who never wash their fruits. $2 \%$ of the people said that they would never wash apples before consumption and similar was stated in the fresh produce survey in which $6 \%$ of the consumers said they seldom or never wash fresh produce (Li-Cohen and Bruhn, 2002). Furthermore, a significant number of people were found to wash with water with tap water only which is $49 \%$ whereas in the literature it was established that 5\% and 24\% dry wipe or wash their fresh produce with water only, respectively (Li-Cohen and Bruhn, 2002).

As in figure 3, it was established that the majority of the respondents got a knowledge score of 5 or above and only 23 out of 72 respondents have scored 4 or less. This implies that the overall level of knowledge is fairly good among people and that there is a need for an extra bit for them to know in order to follow safest practice to wash in order to get rid of the pesticide residues on apples. In addition, the maximum numbers of wrong responses were received for the two knowledge questions: "Does peeling the apples before eating get rid of all pesticides?" and "Do you think even the minimal amount of pesticides, if any present; will have ill effects on human health?" where the percentage of wrong responses was $51 \%$ and $52 \%$ respectively. Therefore, the risk communication messaging must be able to alert about the correct information for the above questions i.e. peeling the apples doesn't remove all the pesticides and there is a limit called maximum residue limit (MRL) that is allowed on food commodities by Health Canada, that will have no effect to minimal effect.

Analysis indicated that there is no association between educational level and effective washing of apples. This was found to contradict the literature where a study shows that there is an association between the level of literacy and food safety practices. (Sudershan, Rao, Rao and Polasa, 2008) This could be expected due to the fact that further education enables consumers to undertake safe practices while handling produce. This, furthermore, suggests that understanding of chemicals on pesticides is not clearly reflected by the educational level primarily because the concept of effective washing is yet evolving with upcoming research and the knowledge has not yet been transferred to the general public. It is possible that the consumers are misinformed about the safe practice of washing fruits. This reinforces the need of effective risk communication to enhance the behaviour that would minimize the amount of 
chemicals in our diet and prevent the preventable hazard.

The survey findings suggest that consumer education materials should emphasize safe practices of handling fresh produce especially washing the fruits (apples in this study) to effectively remove the pesticides that are found on them. This reinforces the need of an efficient risk communication and educational outreach that should target not only any specific population rather general public because it would result in better knowledge which has been established to be associated with the effective washing practice to remove pesticides on fruits (apples).

\section{Recommendations}

Based on this study consumers with low knowledge and understanding of pesticides on apples need to be targeted for risk-messaging. People should be educated about the importance of washing their fruits properly, especially apples, since apples are mostly found to have pesticides on them. And by effectively washing the fruit they can avoid the unforeseen hazards associated with consumption of pesticides in their diets over long term. This study reinforces the need to educate the public on safety concerns such as washing the fresh produce, in order to prevent hazards in general, both chemical and biological. The study reinforces the importance of washing the produce properly well before consumption.

The advantage of rinsing/washing is not only the removal of microbes bur also the removal of a significant percentage of pesticides that could be found on produce and in turn prevent the chronic toxicity resulting from certain chemicals. EHOs play an important role in education of the public and risk communication. The study proves that out of the various factors such as educational level, knowledge level, gender, having children, preference for organic vs. non-organic- the level of knowledge and understanding of pesticides is found to be associated with the effective washing of the fruit. The study gives a better understanding of the knowledge level of the public and the specific risk messages that need to be communicated. As it is found that the public is concerned about the presence of chemicals on apples, therefore, educating them about the correct ways of washing the fruits (apples) that includes washing the fruit and then drying the fruit with paper towel is extremely important. Consequently, the results of the study should be used in the future for effective risk communication and risk management techniques.

\section{Limitations}

Due to the restricted funds, time and resources there were a few limitations of this study. The first limitation is the method of data collection. Participants were only obtained through the internet, which mainly attracted participants living in urban settings and lack of response from those living in rural settings led to a gap in the analysis. Therefore, the result of the data analysis could be biased since the people living in urban settings have different attitude toward food safety as compared to people in rural areas as they have direct experiences with the food production from the farm to fork; and correspondingly that may change their perception towards washing of the fruits. 
Another limitation of the design of the study was that the data collection method impacted the randomness of the study. The respondents were not well distributed in all groups; fewer responses were obtained from older people. The study mainly reflected the perceptions of school-going age groups (1945 years) as most of the respondents were pursuing some study. The snow ball effect lead to an increase in responses, however it decreased the variety of respondents. This representative sample population impacted the accurate reflection of the total population.

The scope of the study was also limited in terms of types of fruits as well. People might have different perception about different fruits and hence differently wash them. In addition, the subjectivity of some of the questions on the survey impacted the analysis and results. For example, question regarding washing of organic vs. non-organic apples and the reason was very subjective and could have been misinterpreted.

\section{Future Research Suggestions}

For further research on the topic of effectiveness of washing to remove pesticides from fruits, a chemical analysis can be done to find out the residual concentration on different fruits after washing. To simplify the chemical analysis using Gas Chromatography - Mass Spectrometry, the pesticides of interest can be applied on the apples by spraying or rinsing to analyse the effectiveness of washing using various techniques.

Further research could also be performed to analyze public's perception about various different fruits and vegetables such as leafy greens as they tend to retain pesticides on them. A study should be done to find out how people follow safe food handling practices such as washing hands before handling food and hygiene practices between handling meats and fruits. A quantitative and qualitative study can be done to find out the knowledge, attitude, beliefs and practices regarding handling of food to minimize chemical and biological contamination.

In terms of risk messaging, further research should be done to determine the effective methods to communicate the messages to the public regarding safety concerns; this could include newer technologies like social media and apps.

\section{Conclusion}

The only demographic to have an association with the effectiveness of washing the fruit (apples) is the knowledge and understanding of pesticides on fruits. People tend to wash their fruit effectively if they are aware of the chemicals present on fruit. Whereas other demographics such as age, gender, educational level or having children are not associated with the effectiveness of washing the fruit. The idea - if you want to change the behaviour of the public, it is important to educate them first to understand the importance of that behavior - is reinforced here. It is important for public officials to educate the general public regarding pesticides on apples and effective washing to remove these pesticides.

The study reinforced the importance of washing the produce properly well before 
consumption. Consequently, the advantage of rinsing/washing is not only to get rid of disease causing microbes but at the same time to remove a significant percentage of pesticides that could be found on produce and in turn prevent the chronic toxicity resulting from certain chemicals. Also, the study helped analyze if the busy adults and young kids wash their produce properly in a way that will get rid of the pesticides. EHOs play an important role in education of the public in various realms of life. The study will prove to be an effective message to educate the public regarding the importance of properly washing the produce and at the same time, method of effectively washing it. The results of the study can be used in the future in effective risk communication and risk management techniques.

\section{Competing Interests}

The author declares that they have no competing interests.

\section{$\underline{\text { References }}$}

Arya, N. (2005). Pesticides and human health: Why public health officials should support a ban on non-essential residential use. Canadian Journal of Public Health, 96(2), 89-92. Retrieved from http://0search.proquest.com.innopac.lib.bcit.ca/ docview/232010451 ?accountid $=26389$

Bienkowski,B. (2014). Pesticides use by farmers linked to high rates of depression, suicides. Environmental Health News Retrieved from http://www.environmentalhealthnews.or g/ehs/news/2014/oct/pesticidesdepression
Canadian Food Inspection Agency. Acts and Regulations. (n.d.) Retrieved from http://www.inspection.gc.ca/about-thecfia/acts-andregulations/eng/1299846777345/129984 7442232

Cooper, J. Dobson, H. (September,2007). The benefits of pesticides to mankind and the environment. Crop

Protection.26(9)1337-1348. DOI: 10.1016/j.cropro.2007.03.022. Retrieved from

http://www.sciencedirect.com/science/ar ticle/pii/S026121940700097X\#

Dorothea, F. Sue, C. Wing, F. Andre, F. Andre, B. Mark, S. (2008) Captan residue reduction in apples as a result of rinsing and peeling. Food Chemistry, 109 (2008), 790-796. DOI: 10.1016/j.foodchem.2008.01.061. Retrieved from http://www.sciencedirect.com/science/ar ticle/pii/S0308814608001180

Food and Drug Regulations (C.R.C., c.870). (n.d.) Retrieved from http://lawslois.justice.gc.ca/eng/regulations/C.R.C., c. 870/page-158.html\#h-109

Food and Drugs Act (Canada) (R.S.1985, c.F27). (n.d.)Retrieved from http://lawslois.justice.gc.ca/eng/acts/F-27/page2.html\#h-5

Health Canada (2012) Maximum Residue Limits. (n.d.) Retrieved from http://prrp.hc-sc.gc.ca/mrl-lrm/index-eng.php

Integrated Pest Management Act (S.B.C.2003, c.58). (n.d.) Retrieved from http://www.bclaws.ca/Recon/document/I D/freeside/00_03058_01

Integrated Pest Management Regulation (Reg.604/04). (n.d.) Retrieved from http://www.bclaws.ca/civix/document/id /complete/statreg/604_2004

Kegley, S.E., Hill, B.R., Orme S., Choi A.H., (2014). Pesticide Action Network, 
North America PAN Pesticide

Database. Retrieved from

http://www.pesticideinfo.org/Detail_Che

mical.jsp?Rec $\mathrm{Id}=\mathrm{PC} 120$ and

http://www.pesticideinfo.org/De

tail Chemical.jsp?Rec Id=PC41373

Kong, Z., Shan, W. Dong, F. Liu, X. Xu, J, Li,

M. Zeung, Y. (2012). Effect of home

processing on the distribution and

reduction of pesticide residue in apples.

Food Additives and Contaminants, 29(8), 1280-1287.

DOI.org/10.1080/19440049.2012.69034

7 Retrieved from

file:///C:/Users/Owner/Downloads/7768 6984.pdf

Li-Cohen, A. E., \& Bruhn, C. M. (2002). Safety of consumer handling of fresh produce from the time of purchase to the plate: a comprehensive consumer survey.

Journal of Food Protection $®$, 65(8), 1287-1296.Retrieved from:

http://www.ingentaconnect.com.proxy.li

b.sfu.ca/content/iafp/jfp/2002/00000065/ $\underline{00000008 / \operatorname{art} 00013}$

Looney, H. (2013, May 21). The worst and the best foods for pesticide levels. Global News. Retrieved from http://globalnews.ca/news/579037/thebest-and-worst-foods-for-pesticidelevels/

Lozowicka, B. (2014). Health risk for children and adults consuming apples with pesticide residue. Science of Total Environment, 502(2015), 184-198. DOI: 10.1016/j.scitotenv.2014.09.026.

Retrieved from http://www.sciencedirect.com/science/ar ticle/pii/S0048969714013369

Luymes, G. (2007). Canadians living normal lives exposed to chemical killers. CanWest News Retrieved from http://0search.proquest.com.innopac.lib.bcit.ca/ docview/460887556? accountid=26389
Michaels, B., Gangar, V., Schattenberg, H., Blevins, M., \& Ayers, T. (2003). Effectiveness of cleaning methodologies used for removal of physical, chemical and microbiological residues from produce. Food Service Technology, 3(1), 9-15. DOI: $10.1046 /$ j.14715740.2003.00063.x. Retrieved from: http://onlinelibrary.wiley.com.proxy.lib. sfu.ca/doi/10.1046/j.14715740.2003.00063.x/full

Ministry of Agriculture BC. Pesticide Registration. (n.d.) Retrieved from http://www.al.gov.bc.ca/pesticides/j_3.h $\underline{\mathrm{tm}}$

Ministry of Agriculture BC (2013). Prevention and Management of Apple Maggot in Commercial Orchards in British Columbia. Retrieved from http://www.agf.gov.bc.ca/cropprot/tfipm lapplemaggot.htm

Ministry of Agriculture and Lands. (2009) BC Good Agricultural Practices Guide. p119.Victoria, BC: Queen's Printer for British Columbia.

Perkel, C. (2006, Jul 23). More than 20\% of fruit and vegetables sold in canada show traces of pesticides. Canadian Press NewsWire Retrieved from http://0search.proquest.com.innopac.lib.bcit.ca/ docview/328680311? accountid=26389

Pest Control Products Act (Canada) (R.S.,c.P9,s.4) (n.d.) Retrieved from http://lawslois.justice.gc.ca/eng/acts/P-9.01/page$\underline{1 . h t m l}$

Pest Control Products Regulations (Canada) (C.R.C., c.1253, s. 45(1) (2)). (n.d.)

Retrieved from http://lawslois.justice.gc.ca/eng/regulations/SOR2006-124/page-1.html

Pesticide Action Network North America (PANNA). Limitation of the ecotoxicity data. PAN Pesticide Database.

Retrieved from 
http://www.pesticideinfo.org/Docs/ref_e cotoxicity1.html\#CaveatsEcotox

Pesticide Action Network North America

(PANNA). What's on my food? (n.d.)

Retrieved from

http://www.whatsonmyfood.org/food.jsp

?food $=$ AP

Rasmusssen, R. R., Poulsen, M. E., \& Hansen,

H. C. B. (2003). Distribution of multiple pesticide residues in apple segments after home processing. Food additives and contaminants, 20(11), 1044-1063.

DOI:10.1080/02652030310001615221

Retrived from:

http://www.tandfonline.com.proxy.lib.sf

u.ca/doi/abs/10.1080/026520303100016

15221\#.VMHvtfldXT8

Ritchie,D. Sutton,J. Walgenbach,J. (2013).

Disease and Insect Management in the

Home Orchard. NC State University.

Retrieved from

file:///C:/Users/Owner/Downloads/Disea

se\%20and\%20Insect\%20Mtg\%20In\%20

the $\% 20$ Home $\% 20$ Orchard $\% 20$ -

\%20REV1012.pdf

Scheuren, F. (2004, June). What is a Survey?.

American Statistical Association.

Retrieved from

http://www.amstat.org/sections/srms/pa

mphlet.pdf

Statistics Canada. 2010. Survey methods and practices. Retrieved from http://www.statcan.gc.ca/pub/12-587x/12-587-x2003001-eng.pdf

Sudershan, R. V., Rao, G. S., Rao, P., Rao, M. V. V., \& Polasa, K. (2008). Food safety related perceptions and practices of mothers-A case study in Hyderabad, India. Food Control, 19(5), 506-513.

Retrieved from:

www.ingentaconnect.com.proxy.lib.sfu. ca/content/iafp/jfp/2002/00000065/0000 $\underline{0008 / \operatorname{art} 00013}$
United States Department of Agriculture (USDA) (May, 2012) Pesticide Data Program Annual Summary 2010. Retrieved from http://www.ams.usda.gov/AMSv1.0/getf ile?dDocName $=$ stelprdc 5098550

United States Environment Protection Agency (USEPA) (April 2008). Pesticide Fact

Sheet. Retrieved from http://www.epa.gov/pesticides/chem sea rch/reg_actions/registration/fs_PC090100 01-Apr-08.pdf

Walter, J. Terri, L. Arsenault, H. and Mary, J. (2000) Reduction of Pesticide Residues on Produce by Rinsing. Journal of Agriculture and Food Chemistry 48(2000), 4666-4670.

DOI:10.1021/jf0002894. Retrieved from http://pubs.acs.org.proxy.lib.sfu.ca/doi/p dfplus/10.1021/jf0002894

Weir, E. (2002). Identifying and managing adverse environmental health effects: A new series. Canadian Medical Association.Journal, 166(8), 1041-3. Retrieved from Proquesthttp://0search.proquest.com.innopac.lib.bcit.ca/ docview/204782978? accountid=26389 